\title{
Rostro deshecho. Por un arte menor y sus alcances políticos en Deleuze
}

\author{
Borja Castro-Serrano ${ }^{1}$ \\ Universidad Andrés Bello (Chile) \\ Cristian Fernández Ramírez² \\ Universidad Andrés Bello, Universidad de Chile (Chile)
}

Recibido: mayo 23 de 2016. Revisado: julio 12 de 2016. Aceptado: septiembre 7 de 2016

Referencia formato APA: Castro-Serrano, B., \& Fernández, C. (2016). Rostro deshecho. Por un arte menor y sus alcances políticos en Deleuze.

Rev. Guillermo de Ockham, 14(2), 43-52. doi: http://dx.doi.org/10.21500/22563202.2651

\section{Resumen}

El presente texto tiene por objeto evidenciar una de las posibles vinculaciones entre arte y política en el pensamiento de Gilles Deleuze. Para lo anterior, se trabajará con base en la formulación del proyecto baconiano que Deleuze enuncia en su texto Lógica de la sensación y que tiene por principio deshacer el rostro. Dicho esto, desarrollamos el concepto de rostridad o rostrificación que el autor teoriza de modo crítico en contraposición al rostro deshecho, mostrando de esta manera las vinculaciones entre el arte y la política. Se concluye con la idea de que un arte menor y una política menor afectarían y atravesarían este proyecto (político) baconiano que el autor llama "deshacer el rostro".

Palabras clave: Deleuze, política, arte, rostro, Bacon

\section{Undone face. For a minor art and its political extents in Deleuze}

\section{Abstract}

This paper aims to highlight one of the possible links between art and politics in the work of Gilles Deleuze. In order to undertake this analisis, we work based on the formulation of the "Baconian project" Deleuze presented in "Logic of sensation" and which begins to undo the face. That being said, we will develop the concept of faciality or rostrification that the the author criticizes as opposed to undoing the face, showing the relations between art and politics. The article concludes with the idea that a minor art and a minor policy effect and cut through this Baconian project the author calls "undo the face".

Keywords: Deleuze, politics, art, face, Bacon

* Este artículo es producto de la investigación Conicyt/Fondecyt de iniciación, 11150317

1. Doctor en Filosofía. Investigador principal Fondecyt de iniciación. Correo electrónico: francisco.castro@unab.cl Av. República 252, Santiago de Chile. .

2. Magíster en Filosofía. Tesista Fondecyt de iniciación, Correo electrónico: cfernandezramirez@ug.uchile.cl 


\section{Rosto desfeito. Pôr um arte menor e seus alcances politicos em Deleuze}

\section{Resumo}

O presente texto como objetivo mostar uma das possíveis relaçôes entre arte e política no pensamento de Gilles Deleuze. Para o anterior, se vai a trabalhar com base na formulação do projeto baconiano que Deleuze mostra en seu texto Logica da sensaçáo e que tem pôr principio desfazer o rostro. Dito isto, desenvolvemos o conceito de rostridad ou rostrificación que o autor teoriza de modo critico em oposição ao rsotro desfeito, mostrando que esta maneira as as ligaçôes entre arte e política. Conclui-se com a ideia de que uma arte menor e uma politica menor afetaria e atravessaria este projeito (político) baconiano que o autor chama "desfazer o rostro".

Palavras-chave: Deleuze, politica, arte, rostro, Bacon

\section{Introducción}

En 1978 Gilles Deleuze dictó una memorable conferencia en la Escuela Nacional Superior de los Oficios de la imagen y el sonido (Femis), ${ }^{3}$ que fue transcrita con el título ¿Qué es el acto de creación” (Deleuze, 2007). En ella, Deleuze establece una importante relación y a su vez una extraña vinculación ${ }^{4}$ entre arte y acto de resistencia. Esta relación, además de parecernos sugerente, nos permitirá ahondar en nuestro objetivo principal: evidenciar una de las relaciones y vinculaciones posibles entre arte y política, con base en el concepto de rostro que el pensamiento de Deleuze elabora y despuntando por un lado, el concepto de rostridad o rostrificación que se teoriza críticamente, en contraposición, por otro lado, al rostro deshecho a partir del proyecto artístico de Bacon.

Dicho lo anterior, volvamos a la conferencia con la que pretendemos introducir estas vinculaciones entre arte y política para llegar a la noción de rostro y preguntémonos: ¿qué relación guarda un acto de creación con el arte y cómo este se piensa en tanto acto de resistencia? ¿Por qué para Deleuze, el arte sería considerado un acto de resistencia y por ello posible de vincular con la política? Buscando alguna clave, el filósofo francés se pregunta y se contesta: "¿Qué relación hay entre las luchas de los hombres y la obra de arte? La más estrecha y para mí, la más misteriosa" (Deleuze, 2007, p. 289). Visualizamos, entonces, la pertinente relación entre arte y política en cuanto es el mismo Deleuze quien expone tal relación. Y si bien sabemos que el desarrollo de ambos términos y su "misteriosa vinculación" se presenta de modo extenso en su obra -pues Deleuze intenta conectar las luchas de los hombres con formas de vida y formas de pensamiento diversas- lo relevante aquí consiste en que este punto deja ver el común entre arte y política en cuanto los actos de creación son modos de resistencia.

Y si profundizamos aún más a favor de contextualizar esta vinculación que creemos pertinente, podemos decir que si el arte es pensado como un acto de resistencia $-y$ por tanto político- es porque este se expresa en sus potencialidades como contra-información. "No hablaremos de obra de arte; digamos simplemente que hay contra-información" (Deleuze, 2007, p. 288). Surgen aquí diversas preguntas que transitan desde el estatuto de la obra de arte o, incluso, de un "sistema de las artes"s hasta preguntas que gravitan sobre el problema de la información y con ello de la comunicación. Y si bien estas preguntas desbordan y escapan al objetivo de nuestro trabajo, creemos necesario llamar su atención a partir de la misma enunciación que Deleuze hace en tal conferencia: cuanto la "obra de arte" como toda "contra-información" se diferencian del ámbito de la comunicación y del control, pues "la información

3. Fondation européenne pour les métiers de l'image et du son.

4. Más detalles sobre la "extraña vinculación" entre arte y política que referimos, va en la línea de lo que Ordóñez (2011) establece como la producción de acontecimientos que competen al arte, la filosofía y la ciencia en Gilles Deleuze, cuestión clave para nutrir también su novedoso pensamiento político.

5. Sería erróneo creer que Gilles Deleuze considera la producción artística en los marcos del arte, simplemente y gracias a una metodología de reconocimiento que permite un sistema homogeneizado y estandarizado basado en rasgos estructurales que caracterizarían su existencia. El autor más bien describe las características de la producción artística como parte de un sistema abierto de las artes que responden a ciertos problemas que le competen, comunican y los hacen común. En este sentido y para efectos de nuestro escrito, la literatura y la pintura si bien comparten el estatuto que los identifican con el arte, lo hacen por razones particulares que no pueden verse nominadas por un "sistema de las artes". "Nosotros no creemos en modo alguno en un sistema de las bellas artes, sino en problemas muy diferentes que encuentran sus soluciones en artes heterogéneas. El arte nos parece un falso concepto, únicamente nominal” (Deleuze \& Guattari, 2002, p. 299). Hay más bien en Deleuze, una perspectiva que hace posible la comunicación -no solo de las artes sino también de las ciencias, la filosofía, etc.- con el acontecimiento, que permite vincularlos en la medida en que contienen un elemento de creatividad implicado en la producción de acontecimientos (Ordóńez, 2011). 
es exactamente el sistema de control" (Deleuze, 2007, pp. 286-287). ${ }^{6}$

Establecidas así las cosas, si el acto de creación se piensa no solamente en la obra de arte como acto de resistencia, sino como toda contrainformación, podemos asociar que toda contrainformación escapa y crea para resistir al control, pretendiendo con ello devenir fuera de los alcances de lo que su métrica opera y representa. El arte y la política en su vinculación y tensión en Deleuze, se muestran como potencialidades que buscan transformar la situación en la que se encuentran; participar, crear y recrear activamente en el proceso en el que se ven plegados. ¿¿Será, entonces, el arte o la obra de arte un arma (política) para escapar a las nuevas sutilezas y dinámicas de las llamadas actuales "sociedades de control"?7

De acuerdo con la pregunta recién planteada y con nuestro objetivo a la vista, nuestro itinerario apuntará a esclarecer las relaciones entre arte y política, específicamente bajo la tensión política que se desarrolla a la luz de la noción de rostro (y sus despuntes artísticos en Bacon). Para comenzar, en un primer punto esbozaremos la presentación crítica a la concepción representacional del pensamiento que Deleuze observa en cierta tradición filosófica y se prolonga comúnmente a determinadas formas de comprender e interpretar el arte y la política, cuestión que impacta en la noción del rostro. A partir de aquí, en un segundo punto trabajaremos el concepto de rostro como rostridad/rostrificación que visibiliza un cierto tipo de política. Esta relación última muestra nuevas herramientas del poder que complejizan las dinámicas y generan una hipersubjetivación y una hipersignificancia en cuanto el rostro funcionaría como captura de cualquier intento de resistencia (Deleuze \& Guattari, 2002).

En contraposición a lo anterior, en nuestro tercer punto mostraremos otro tipo de rostro que Deleuze trabaja: el rostro deshecho. Es a partir de los análisis de la pintura de Francis Bacon que surge el llamado "proyecto baconiano", el cual tiene también una formulación política específica. Desde aquí podremos desentrañar nuevas coordenadas y potencialidades para abordar el encuentro entre arte y política en el que destacan la relación, las resonancias y las interferencias posibles que coexisten con una potencial política. Lo interesante $-y$ que Deleuze destaca en este último sentido- radica en que la lógica de la sensación que caracteriza el espacio pictórico baconiano remece y se aleja del campo de lo representacional entre un sujeto y un objeto (Deleuze, 2002b). Aquí reside el potencial revolucionario de la pintura baconiana, pues ella pondría en jaque -borrando y deshaciendo- los dominios y la formación de códigos pictóricos a los que estamos acostumbrados. Así, la importancia común para el arte y la política según el proyecto baconiano, evidenciaría la capacidad de abrir una zona informal y nueva de la experiencia, en la cual objeto y sujeto se pierden desregulando y transgrediendo de esta manera los sentidos y los códigos preestablecidos (como los de la rostridad), para encontrar en sus variaciones nuevas potencialidades, articulaciones y encuentros.

Por último, en el cuarto apartado y de acuerdo con lo que Deleuze trabaja en el arte pictórico de Bacon, trazamos un lazo común entre las implicaciones del proyecto baconiano de deshacer el rostro con la "literatura menor" que Deleuze y Guattari observan en Kafka. Así, la comprensión de un arte menor que se enuncia en el título del presente artículo -en este caso relativo a la pintura y la literatura- debe develarse a partir de una concepción irreductible a un juicio puramente imaginario, representativo, metafórico o simbólico del arte. Lo anterior, sostiene que un arte menor debe pensarse con base en usos menores que deforman y deshacen la norma mayor y que en su formulación política ubican toda una potencia revolucionaria que se aleja y desborda los marcos representativos y preestablecidos de las estructuras dominantes de poder y control.

\section{La crítica al pensamiento representacional: arte, política y filosofía}

$\mathrm{Al}$ adentrarnos en el terreno del rostro, la política y los modos de pensar, cabe afirmar que para Deleuze la

6. Aclaramos que las preocupaciones sobre el lenguaje y la comunicación en Deleuze tienen grados de variación, según lo que podríamos denominar "épocas" de producción teórica. Sobre esta base, acudiremos a la perspectiva más pragmática del autor, en la que el problema ya no se enfoca a una cuestión de sentido (Deleuze, 1994) sino de uso. Aquí su orientación tiene en cuenta la radical importancia de la dimensión social y política del lenguaje como ámbito fundante. Junto a ello se denuncia una instancia operativa en el lenguaje, que se define como una estructura englobante de las significaciones dominantes. Lenguaje y poder se encuentran, por lo que la tarea consiste en mostrar el tipo de régimen de signos dominantes en nuestra sociedad, la uniformación de la enunciación y la constitución de una realidad dominante de lo social (Deleuze \& Guattari, 2002).

7. Deleuze en su post scriptum (1999) hace referencia a un nuevo tipo de sociedad que reemplazarían, bajo la figura de la crisis, a las llamadas sociedades disciplinarias descritas por Foucault. Los centros de encierro, como la cárcel, el hospital, la fábrica, la escuela y la familia, estarían atravesados por una crisis generalizada donde el control del espacio, del tiempo, de los cuerpos y de la subjetividad ya no responden a la configuración del poder disciplinario. Entonces, ya no pueden tener la rigidez y el carácter estático que las caracterizaba. Las sociedades de control, en este sentido, remitirían a otro tipo de coordenadas donde el poder -en razón de la vigilancia, la normalización y el control- toca y visibiliza de una manera más diseminada y difuminada el espacio, el tiempo, los cuerpos y la producción de subjetividad. Su operatoria se basa más en producir e inscribir consignas que remitan a un marco de variación no estable por medio de nuevas tecnologías que confluyen en procesos de normalización. 
rostridad/rostrificación plantea ante todo el problema de equipamientos de poder que involucran formas de producción de subjetividad. Es decir, podemos pensarla como la composición de interacciones complejas y heterogéneas que atraviesan el campo social en función de un orden hegemónico y de normalización que eventualmente toca formas del pensamiento, la política y el arte. Por lo mismo, para Deleuze aparece la necesidad de posibilitar un pensamiento y una vida fuera del reino de la representación y de los cuerpos en cuanto pura organicidad; bajo sus nociones, diríamos que fuera de cualquier imagen dogmática $^{8}$ que se tenga del pensamiento y la vida.

Y frente al entramado recién descrito del rostro-rostridad, Deleuze ejerce una crítica que estima la potencialidad de desorganizar los mecanismos control y se expresa en la enunciación del proyecto baconiano "deshacer el rostro". Este proyecto antirrepresentacional que encuentra su potencial revolucionario en la capacidad de "devenirmenor" del arte y la política en cuanto actos de creación y resistencia, propone necesariamente un nuevo tipo de pensamiento que sale de la concepción representacional. Entonces, esta misteriosa conjunción entre arte y política que desarrollamos en clave rostro nos invita a un nuevo modo de pensar, filosofar y hacer política que toca con el mundo de la sensación y la experimentación. ${ }^{10}$ Volveremos sobre esto.
Las cuestiones recién establecidas son preocupaciones sostenidas por Deleuze a lo largo de su obra y relacionadas con "lo que significa pensar". Esta redefinición de lo que puede significar pensar, nos conecta con un pensamiento que debe estar siempre atento a lo que está deviniendo (Cuevas, 2016). Aquí, Deleuze invoca otro tipo de pensar, a saber, el pensamiento nómada, ${ }^{11}$ un pensamiento que se entrelaza y cruza con diversos elementos -filosofía, arte y ciencia- para crear algo nuevo; se erige, en palabras del francés, como una verdadera "máquina de guerra" ${ }^{12}$ que moviliza y articula devenires.

En contraposición a este pensamiento nómada de Deleuze, irrumpen la comprensión y la crítica a la concepción representacional del pensamiento: lo que la tradición filosófica históricamente instauró y Deleuze llamó la "imagen dogmática del pensamiento”. Este último se caracteriza principalmente por ser un modelo sedentario de la identidad, de lo ancestral, de la forma, de la representación, de la norma y del sujeto. Es un pensamiento esclavizado por la función del par identidad-representación que siempre asemejará al pensamiento como un ejercicio de mero reconocimiento; reconocimiento de un modelo por representar determinado por su forma y provisto de órganos y funciones siempre asignados a sujetos totalmente definidos e identificados.

Lo anterior para Deleuze reviste graves consecuencias (incluidas las del arte y la política), ${ }^{13}$ pues este pensamien-

8. Respecto a la cuestión del pensamiento dogmático, Deleuze se está refiriendo críticamente al pensamiento de Kant, pues este último es quien había advertido la imposibilidad de construir conceptos, en tanto la intuición (facultad de recepción como sensibilidad) como el concepto (facultad activa de la representación junto con la razón y la imaginación) transitaban por tramas distintas. Sin embargo, y dado lo anterior, la concepción kantiana siempre se instaló como una filosofía crítica porque fue ella quien denominó pensamiento dogmático al racionalismo de Descartes, Leibniz y Spinoza, los cuales, a su vez, establecían que se debía pasar de la intuición al concepto, siendo posible ese tránsito y la posibilidad de construir la existencia, sin examinar los límites de la razón pues se confiaba en ella. Por lo tanto, Deleuze a modo de rebelión contra Kant, critica la filosofía de este último, como la filosofía dogmática, y construye su frase: "La filosofía es creadora de conceptos", ironizando respecto al pensamiento kantiano (Deleuze, 2008). Así, en su obra más tardía (Deleuze \& Guattari, 1999) posibilita al pensamiento filosófico como creador de conceptos en conexión con el devenir y la vida.

9. La cuestión del "devenir-menor", y con ello el problema de las minorías, lo tematizamos más adelante, pues creemos que vincula estrechamente arte y política. En este sentido, las claves de lectura entregadas por Sauvagnargues (2006) sobre la relación de conceptos deleuzeanos tales como menor y mayor, normal y anómalo, se tornan esclarecedoras para profundizar en clave política la tensión y variaciones dadas en el arte entre los organismos de control y los elementos de desorganización. Pensamos que bajo esta clave de lectura es posible trabajar la idea de un "arte menor" que deviene ajeno a las estrategias de dominación. Esto mismo nos lleva a la idea de un "arte menor" y sus efectos sobre el campo político, cuestión desarrollada por Deleuze y Guattari (1983).

10. El agenciamiento entre política y arte en Deleuze y Guattari, puede abordarse como una política de la sensación (Alliez, 2004). Este autor precisa una verdadera política de la sensación que se manifiesta como un modo de trazar líneas de vida, como una real forma de devenir-otro por el sentir, en el que se construyen nuevas territorialidades capaces de condensar nuevos y reales devenires. Su sustento político estriba en la lucha que comprende tal composición de devenires, contra las figuras de la organicidad expuestas por su funcionalidad y orden en sus múltiples formas (significante, sujeto, órgano).

11. Deleuze hace referencia a la idea de un pensamiento nómada que se emparenta con un pensamiento que en su ejercicio es capaz de crear y construir conceptos que se articulan en la heterogeneidad y diversidad de problemáticas. Un pensamiento nómada se caracteriza por un desamblaje y desbaratamiento de los códigos establecidos y no remite a las coordenadas de la esencia, ni de la teleología, ni de la trascendencia ni de un siempre necesario retorno al fundamento (Deleuze, 2005).

12. La noción "máquina de guerra" en Deleuze y Guattari refiere a diferentes coordenadas que pasan por los planos histórico, político, artístico, filosófico y científico, entre otros. Destacamos la referencia a la idea de una máquina de guerra en cuanto acentuación de la existencia y potencialidad de una exterioridad que persiste, batalla y se vuelve irreductible a todo sistema y estructura de lo mismo y de la representación, con su particular modo de operar y propia forma de funcionar (Deleuze \& Guattari, 2002).

13. Deleuze deja ver rápidamente las implicaciones políticas que este pensamiento conlleva; por ejemplo, la consideración de una cierta policía del pensamiento capaz de regular la subjetividad en un todo, en un sistema de creencias y de normas obedientes al control. Por ello, la apuesta y la reflexión deleuzeanas consistirán en escapar de estas formas de control como de sus sutiles formas de represión y tecnologías de dominación. "Como sabemos, las fuerzas represivas tienen siempre necesidad de yoes asignables, individuos bien determinados sobre quienes ejercerse. Cuando nos hacemos más fluidos, cuando escapamos a la asignación de un yo, cuando ya no hay hombre sobre el cual pueda Dios ejercer su rigor o que pueda sustituirle, entonces la policía se vuelve loca" (Deleuze, 2005, p. 180).

$46 \varangle$ Universidad de San Buenaventura, Cali - Colombia 
to de la representación no hace más que obstaculizar su propio devenir. Pero el pensamiento para devenir debe expresarse de un modo anti-representacional: renunciar, minar y combatir la noción del modelo a seguir. A su vez, tiene la tarea de hacerle frente a la reducción de lo puramente figurativo, imaginario, analógico y metafórico del pensamiento, que con base en este binarismo (síntesis y correspondencia entre lo idéntico y lo representado) capturan sus potencialidades (Deleuze \& Guattari, 2002).

Dicho en torno a tramas contrapuestas, el pensamiento nómada -aquel del devenir- consiste, en primer lugar, en enfrentar este sedentarismo de la imagen dogmática del pensamiento y su necesidad de clasificación de todo devenir en especies y géneros; o bien, bajo modelos que lo subyugan a los marcos de la identidad. Y en segundo lugar, el pensamiento nómada debe hacer visibles los dinamismos que lo atraviesan; es decir, modos de expresión que articulan un "pensamiento rizomático". ${ }^{14}$ Dicho de otro modo, el pensamiento como heterogénesis se vive en oposición al pensamiento arborescente de la imagen dogmática y esto nos acerca a la vinculación entre devenir y pensamiento, entre devenir y arte.

Ahora podemos volver sobre el mundo de la sensación y de la experimentación en el arte, en cuanto sabemos el rechazo a la concepción representacional del pensamiento. Y a su vez, ahora entendemos cómo la propuesta deleuzeana del pensamiento tiene consecuencias antirrepresentacionistas para el arte. Y si algo Deleuze rescata del arte, es que este se determina a partir de la experiencia concreta de lo sensible fuera de todo modelo de reconocimiento y de la representación: "ningún arte, ninguna sensación han sido jamás representativos" (Deleuze \& Guattari, 1999. p. 195). El arte no es el campo de lo representativo, de la trascendencia o lo normativo o de lo narrativo, sino más bien este se esfuerza por erigir "monumentos con sus sensaciones" (Deleuze \& Guattari, 1999, p. 200).

La creación artística siempre vela por esta independencia de la sensación, proceso que define su propio devenir al resistirse a los modelos hegemónicos y homogeneizadores de la representación que instalan consignas para dar forma única al sentir, el ver y el decir de los sujetos; cuestión que tiene repercusiones políticas. "El arte es el lenguaje de las sensaciones tanto cuando pasa por las palabras como cuando pasa por los colores, los sonidos o las piedras. El arte no tiene opinión" (Deleuze \& Guattari, 1999, pp.
177-178). Así, estas formas contrapuestas de pensamiento que muestran relaciones entre arte y política, impactan en la noción de rostro con sus implicancias políticas.

\section{El problema de la rostridad/rostrificación: la captura política}

Con base en este nuevo tipo de pensamiento propuesto se articula el problema y la crítica de la rostridad o rostrificación con la ya mencionada vinculación entre arte y política. ¿Cómo un análisis de la rostridad puede guiarnos en este entrelazo de arte y política? Este análisis versa entre un tipo de pensamiento representacional frente a uno de la sensación. Así las cosas, el problema crítico de rostridad se abordará a partir de la meseta "Año 0-Rostridad” ( Deleuze \& Guattari, 2002). Es aquí que esta singular noción de rostro (como rostro-rostrificado) permite acercarnos al proyecto baconiano de "deshacer el rostro", el cual comienza en Mil mesetas y se consolida en Francis Bacon. Lógica de la sensación (Deleuze, 2002b).

Bajo la figura del rostro aparecen dos ejes fundamentales -de significancia y de subjetivación-, que se intersectan en un dispositivo que alterna y hace convivir procesos semióticos y procesos de estratificación. Para los franceses, son rasgos de rostridad los que allí se instalan y sin ir más lejos, nuevas sutilezas que el poder despliega. Como hemos dicho, son nuevas herramientas del poder que los diversos elementos que conviven en diferentes registros, regímenes y estratos, deben ajustarse según esta nueva máquina abstracta de rostridad que los produce. "Un niño, una mujer, una madre de familia, un hombre, un padre, un jefe, un profesor, un policía, o hablan una lengua en general, hablan una lengua cuyos rasgos significantes se ajustan a los rasgos de rostridad específicos" (Deleuze $\&$ Guattari, 2002, p. 174).

En este sistema-rostro, estos rasgos se forjan bajo un primer eje semiótico de significancia que neutraliza las expresiones y las conexiones subversivas, y las reemplaza por significaciones dominantes. Y por un segundo eje correspondiente a la subjetividad, que no hace más que constituir espacios de resonancia que seleccionan y se adecuan a un orden dominante, de ahí que decimos que este tipo de rostro genera un tipo de producción de subjetividad. El rostro es redundancia de significancia y resonancia de subjetividad; es decir, el sistema-rostro actúa como pared-

14. Para Deleuze y Guattari, la cuestión del rizoma toma gran relevancia en su obra no como simple modelo de conocimiento, sino como una forma efectiva de comprensión y funcionamiento de la realidad. El rizoma vendría a significar un sistema abierto e irreductible a las formaciones y estructuraciones estáticas, esencialistas o identitarias y que se digan representantes últimos de la realidad. Algo que caracteriza al sistema rizomatico, es su carácter de apertura y su posibilidad de conjuntar elementos y dimensiones totalmente dispares (Deleuze \& Guattari, 2002). 
blanca y agujeros-negros, respectivamente. Este sistema tiene, además, la particularidad y la singularidad de ser el inicio de la aparición del hombre-blanco-occidental-europeo; el ser humano como "ser racional". En este sentido, las campañas de rostrificación como procesos globales, artísticos, políticos, culturales, científicos y sociales, no hacen más que integrar y subsumir toda excentricidad de rasgos inadecuados a ese sistema específico. Lo anterior en función de un trazado particular en un plano de organización que asigna y distribuye los rostros.

Es así como el rostro, su distribución y ordenamiento se vuelven una política, o más bien, una macro y micropolítica-correlación entre lo molar y lo molecular-que se engarza directamente con la producción capitalista actual, con el poder, con la sociedad, el Estado y los medios de comunicación. Al corriente de esta lógica, Deleuze dirá: "El rostro es una política" (Deleuze \& Guattari, 2002, p. 186). Se desenmarañan los acoplamientos que esta política del rostro suscita en cuanto procesos de subjetivación y de significación, restringidos a un conjunto de poder que determinan una específica producción social.

El plano de organización del rostro debe comprenderse bajo el signo de la comunicación y la información que permanentemente recorren las redes del poder y capturan todo elemento de alteridad que no se ajuste a la articulación semiótica -los regímenes de signos- y a los procesos de subjetivación que inicia la rostrificación. Bajo la perspectiva de esta conjunción de diferentes procesos semióticos y de subjetivación (asignando y representando determinadas funciones), se muestra una verdadera pragmática que compromete y exhibe una multiplicación de combinaciones posibles que diferentes instancias sociales manifiestan en su devenir. Por ello, los procesos de rostrificación que tienen lugar pueden presentar dentro de un marco político, al Estado -por ejemplo- bajo los efectos de nuevas resonancias; es decir, la función real del Estado en tales formaciones de rostridad agita persistentemente nuevas modalidades y sofisticaciones de poder.

De hecho, lo que funciona aquí no es la persona ni el rostro como tales. No es su aspecto puramente físico lo que importa o sus meras representaciones institucionales, sino que el rostro pertenece más bien a una constelación compleja en la que el poder no se relaciona solo según la administración que lleva a cabo en un aspecto macromolar. Más bien y ante todo, repercute por la imposición de un modelado de actitudes, de gestos, de enunciaciones y de expresiones a través una enmarañada articulación micromolecular. No solamente serán sus policías, sus ejércitos, sus administraciones y estructuras las que se exhiban como determinantes en sus rasgos políticos, sino que parte de su potencial residirá en la participación de diferentes secuencias de la vida cotidiana, como la escuela, el vecindario, la familia y el inconsciente. Se ve acá todo el potencial micropolítico que abre la cuestión del rostro y la rostrificación. "Nuestra semiótica de hombres blancos modernos, la misma del capitalismo, ha alcanzado ese estado de mezcla en el que la significancia y la subjetivación se extienden efectivamente la una a través de la otra" (Deleuze \& Guattari, 2002, p. 187).

Frente a todo lo anterior los autores aún se preguntan: “¡cómo salir del agujero negro?, ¿cómo traspasar la pared?, ¿cómo deshacer el rostro?” (p. 190). Si el sistema-rostro, o bien, la rostrificación, efectivamente ejercita toda una política, ¡deshacerlo también lo sería! Y tal es el reto de traspasar el rostro, deshacer su organización y provocar devenires. "Deshacer el rostro es también otra política, que provoca los devenires reales, todo un devenir clandestino. Deshacer el rostro es lo mismo que traspasar la pared del significante, salir del agujero negro de la subjetividad" (Deleuze \& Guattari, 2002, p. 192).

Así, las implicancias de deshacer el rostro y sus posibilidades de realización son una cuestión práctica; una articulación de modos positivos y creativos de expresión y enunciación. Con esto estamos más cerca de la articulación entre arte y política de lo que se cree, pues al acercarnos a la emergencia de tales elementos conflictivos, encontramos superposiciones de diferentes tipos, nuevos signos que abren una política del rostro deshecho capaz de expresar nuevos potenciales para una política otra. Tales superposiciones se dan conjuntamente en la búsqueda de producción de lo nuevo, de nuevas máquinas, nuevos roles, una nueva tierra, percepciones, afectos, deseos, creencias, entre otros. Nuevas maneras de afectar y ser afectados.

\section{Deshacer el rostro: el proyecto baconiano como formulación política}

Como ya se sabe, la función de rostridad constituye siempre un modelo mayor, de control, hegemónico y dominante. La rostridad constituye una serie de patrones determinados con funciones, normas y asignaciones específicas. "Nos ha mostrado bajo qué forma el hombre constituía mayoría, o más bien el patrón que la condicionaba: blanco, macho adulto, 'racional', etc.; en resumen, el europeo medio cualquiera, el sujeto de enunciación” (Deleuze \& Guattari, 2002, p. 292). Debemos salir de este sistema de pensamiento que induce a las representaciones y asignaciones para devenir en rostro-deshecho. Este es nues- 
tro destino como humanidad, dicen los franceses: "hasta el punto de que si el hombre tiene un destino, ese sería el de escapar al rostro, deshacer el rostro y las rostrificaciones" (Deleuze \& Guattari, 2002, p. 176). Nuestra labor consiste en acercarnos a esos devenires y una manera de escabullirnos del sistema-rostro es mediante el surgimiento del sistema cuerpo-cabeza (Deleuze \& Guattari, 2002). Esto implica la aparición de una corporalidad otra que surje en Francis Bacon (Deleuze, 2002b). ¿Cómo pensar, ahora, el rostro deshecho?

Es momento de entrar de lleno al proyecto baconiano sobre el que Deleuze cavila junto a Guattari: "La cabeza está incluida en el cuerpo, pero no el rostro" (Deleuze \& Guattari, 2002, p. 175). En una primera instancia, debemos contraponer a la máquina abstracta de rostridad una corporalidad nueva que expresa el sistema cuerpo-cabeza. Esta es una corporalidad que no es organismo y no se focaliza en un intento por precisar "qué es" el cuerpo ni busca fijarlo ni identificarlo, sino que más bien instala nuevos principios rectores frente a la pregunta por el cuerpo; deben indicar ahora el "cómo se usa". Se quiere comprender el cuerpo a partir de sus relaciones diferenciantes, por sus deformaciones y nunca por nociones objetivantes. Esto contribuye a una desterritorialización de los rostros; es decir, un "deshacer el rostro" que en segunda instancia y a partir de la pintura traza registros antirrepresentacionales que hacen visibles las siluetas, las posturas, los colores y las líneas que componen el cuerpo ahora intensivo. "una desterritorialización de los rostros y de los paisajes, en beneficio de cabezas buscadoras, con líneas que ya no imitan ninguna forma, que ya no forman ningún contorno, colores que ya no distribuyen paisajes" (Deleuze \& Guattari, 2002, p. 299-300). En otras palabras, sería la invitación al rostro deshecho que Deleuze ve en su análisis sobre Bacon: aquel sistema cuerpo-cabeza que no es rostro, sino que "la figura es la forma sensible relacionada con la sensación” (Deleuze, 2002b, p. 41).

Ahora es la figura el elemento antirrepresentacional que Deleuze observa en la pintura de Bacon, que antes de ejercerse como el cliché de una historia que violenta por lo representado, instala más bien una violencia de la sensación. Para Deleuze, la pintura de Bacon rompe con lo figurativo y la figuración; es decir, con los órdenes de las formas y de la representación. Lo anterior sería, pues, porque Bacon al pintar la sensación no hace más que captar fuerzas y las hace visibles sin que estas de por sí lo sean. No se trata de reproducir ni de inventar formas, sino de captar fuerzas. La pintura de Bacon que deshace el rostro escapa de lo figurativo, y lo hace creando zonas de indiscernibilidad en donde se encuentran diversos registros y niveles que hacen escapar a la figura de la organización, de lo figurativo y sus modelos.

Lo figurativo (la representación) implica, en efecto, la relación de una imagen con un objeto que se supone que ilustra, pero implica también la relación de una imagen con otras imágenes dentro de un conjunto compuesto que otorga precisamente a cada una su objeto (Deleuze, 2002 b, p. 14). Por ello, debemos entender que el proyecto baconiano es expresado en la pintura -como todo artecomo composición de sensación. Todo arte es agente de deformación del cuerpo y germen que demanda otras contexturas, disposiciones y conexiones con otros dominios sensibles. Es una sensación que "se da en diversos niveles, es de diferentes órdenes o está en varios dominios. [...] Pertenece a la sensación el desarrollar una diferencia constitutiva de nivel, una pluralidad de dominios constituyentes" (Deleuze, 2002b, p. 44).

Asimismo, recordemos que el arte para Deleuze y Guattari (1999) se compone por medio de afectos y perceptos, elementos que, precisamente, pertenecen a la sensación y manifiestan grados de desterritorialización. Estos afectos y perceptos en cuanto fuerzas desestabilizadoras, pueden conectarse con el plano de organización histórico y social dominante, generando así una desterritorialización que violenta tal plano, precipita acontecimientos y produce variaciones en la experiencia. Surgen, entonces, nuevos modos de pensamiento, de expresión, de enunciación y de vida. Para Deleuze, todo un mundo se anuncia: "Tan solo el mundo de las velocidades y de las lentitudes sin forma, sin sujeto, sin rostro" (Deleuze \& Guattari, 2002, p. 284).

Se produce un quiebre con la organización de rostridad en este correlato entre arte y política y se traspasa el poder soberano para liberarnos del orden de la representación, la organicidad, la significancia y el sujeto. La cuestión se esclarece respecto del panorama político del rostrodeshecho y surgen múltiples encuentros en comunión de una multiplicidad colectiva que provoca devenires, velocidades, celeridades y metamorfosis; verdaderas potencias de afectos y perceptos de las que el arte y la política dependen.

\section{Rostro deshecho: sobre un arte menor}

Así dispuestas las cosas, profundicemos más acerca del rostro deshecho y establezcamos que mediante la figura acontecen al menos dos cuestiones esenciales en la que la primera implica la segunda. Lo primero es que Bacon para Deleuze "constituye una zona de indiscernibilidad, de indecibilidad" (Deleuze, 2002b, p. 30). Y segundo, este proyecto de deshacer el rostro en Bacon en cuanto constitución de zonas de indiscernibilidad, nos permite 
situar una política dependiente de toda una potencia de multiplicidad en el que se ve envuelto el ser humano. Entre tales potencias se encuentran los "devenires-animales" que trazan toda una política menor común al proyecto de deshacer el rostro tomado desde Bacon:

esta política se elabora en agenciamientos que no son ni los de la familia, ni los de la religión, ni los del Estado. Más bien expresarían grupos minoritarios, u oprimidos, o prohibidos, o rebeldes, o que siempre están en el borde de las instituciones reconocidas [...], tanto más secretos cuanto que son extrínsecos, en resumen, anómicos (Deleuze \& Guattari, 2002, p. 252).

¿Qué nos permite relacionar al animal con el arte y la política para ser una contrarrostrificación? Una de las líneas por las que el animal se relaciona con el arte y la política en Deleuze, es con base en su potencia intensiva y anómica, su esencial "anomalía" que contiene afectos, se muestran como verdadera potencia de minorización (como conjunto de posiciones que refieren a una multiplicidad) y afectan una norma mayor. "El animal es un anómalo" (Sauvagnargues, 2006, p. 56). Y justamente esta anomalía, como efecto y ejercicio activo de un deshacerse de ciertas determinaciones y especificaciones de la norma y la organización, se encuentra en el rostro deshecho de Bacon. Ahora bien, para rescatar sus resonancias políticas debemos atender a lo que Sauvagnargues (2006) hace notar sobre la relación que existe entre lo normal y lo anómalo, ambos relativos a la pareja de lo mayor y lo menor. ${ }^{15}$ Son estos conceptos los que nos permitirán conectar nuevamente los planos del arte y la política (algo así como resistencia, afecto y multiplicidad).

Para comprender esta problemática debemos acudir a otra de las producciones artísticas que Deleuze trabaja para articular arte y política. La literatura kafkiana les permitirá a Deleuze y a Guattari hablar de una literatura menor, una literatura que no se reduzca a una concepción puramente imaginaria, representativa, metafórica o simbólica, sino a una literatura maquínica y sobre todo, a una creación menor político-literaria de Kafka. "Nosotros no creemos sino en una experimentación de Kafka; sin interpretación, sin significancia, sólo protocolos de experiencia” (Deleuze \& Guattari, 1983, p. 17). Este uso menor de la lengua mayor en Kafka, esta deformación de la norma mayor ubica toda una potencia revolucionaria en la literatura, una conversión revolucionaria en el arte: la posibilidad de una enunciación colectiva.

De este modo, lo menor es una provocación, una polémica, una tensión que instala siempre un problema. Siguiendo la literatura menor:

¿Cuántos viven hoy en una lengua que no es la suya? ¿Cuánta gente ya no sabe ni siquiera su lengua o todavía no la conoce o conoce mal la lengua mayor que está obligada a usar? Problema de los inmigrantes y sobre todo de sus hijos. Problema de las minorías. Problema de una literatura menor, pero también para todos nosotros [...] (Deleuze \& Guattari, 1983, p. 33).

Ahí radica nuestro problema y el de la literatura menor: ¿cómo volvernos extranjeros en nuestra propia lengua? (Deleuze \& Guattari, 2002). El devenir de una lengua menor desencadena un cierto ejercicio de "minoración" en esta extranjería, como estipula Sauvagnargues (2006); un desequilibrio de las normas mayores y dominantes. Con este matiz a la vista en el que la politización y la colectividad se hacen presentes en la escritura, podemos tratar la problemática de la creación literaria con base en los usos, transformaciones, desorganizaciones y deformaciones inmanentes de la lengua.

Tal como en Bacon, el arte no se preocupa por contar historias, no se propone narrar sucesos ni comunicar consignas e información alguna, formar metáforas o simbolismos con lo expresado. No hay asignación o designación y tampoco se habla en un sentido figurado. Más bien, intenta hacer y generar usos intensivos de la deformación, o del mismo proceso efectivo y positivo de minoración que no representa, ni significa, ni imita modelos trascendentes e invariables. Se abren secuencias intensivas, asubjetivas (preindividuales, despersonalizas y sociales), asignificantes del arte.

15. Las implicaciones que llevan la teorización de lo menor y las prácticas mismas que ello produce, se inscriben en algunas de las preocupaciones de Deleuze y Guattari sobre un lenguaje intensivo en la literatura. El soporte para la serie terminológica del par menor-mayor, es abordado por ambos autores desde Kafka. Por una literatura menor (1983), recuperando una lectura política que no tome lo menor como un mero objeto de estudio histórico y de abstracción ni tampoco como una mera estructura numérica. Se quiere vislumbrar una politización de las prácticas sobre la escritura en permanente variación, en su imposible captura absoluta, donde el asentamiento hegemónico, en este caso de una lengua, presupone su propia fuga. Su instauración y formación es coexistente a su propia desmembración y deformación. Por eso, si bien sus estudios se entrecruzan constantemente con los procesos históricos y sociales, su vinculación a las luchas que ahí se dan no son del todo determinantes para definir esta doble serie. Lo menor, siempre se escapa. De todas formas, esto no nos impide ver la situación particular de Kafka, en su contexto social, cultural e histórico; es más, nos ayuda a ampliar el problema sociolingüístico que por ejemplo se dio en Praga. Así, lo que les importa a Deleuze y Guattari es el uso y politización inmanente de la enunciación (Cuevas, 2016). Una especie de aminoración de la propia lengua mayor en sus usos creadores, en esta compleja tensión del dominio y hegemonía de una lengua mayor. Y según ambos autores, en sus usos menores queda fragilizada interiormente y la arrastra a un nuevo lenguaje. Nuestro énfasis entonces, estará dado en la cuestión del uso, su posible politización y un cierto registro colectivo de enunciación (Deleuze \& Guattari,1983; Sibertin-Blanc, 2010).

$\mathbf{5 0}<$ Universidad de San Buenaventura, Cali - Colombia 
De esta manera, la minoración no se reduce a una contestación abstracta de la norma establecida. Designa un proceso positivo que califica al arte bajo el aspecto de su material (materia expresiva), de su campo de recepción (cuerpo social, medio de individuación) y de su "autor" o singularidad creadora. Materia, sociedad, artista: con estos tres criterios tenemos filosofía del arte (Sauvagnargues, 2006, p. 61). ${ }^{16}$

Lo anterior sería una dimensión del acontecimiento que instala el arte y permite una experimentación frente a cualquier asignación, significación e interpretación dominante. Se visualizan auténticas zonas de desterritorialización que generan movimientos, velocidades, aceleraciones, fuerzas y vectores poliformes y precipitan acontecimientos fieles al devenir que liberan fugas impensadas y crean algo nuevo.

De esta forma, el común elemento del trabajo creativo hace inseparable el ejercicio de experimentación inagotable e impredecible en el arte, a saber, la política y el pensamiento, pues no hacen más que resistir (crear en este caso es experimentar y resistir) ocupando la fórmula enunciada por Deleuze y Guattari, que articula la posibilidad y la capacidad de hacer devenir nuevas potencialidades. Inclusive, se hace aparecer la realidad de otro modo, inaugurando potencias indeterminadas que resisten al orden actual. En este sentido, lo que permite esta articulación y relación es la capacidad de un devenir del arte, una fuga de la política que no se agota ni fatiga en las representaciones sociales o en las metáforas de la realidad, sino que en sí es concreta y positiva, es decir, autónoma. Nuevos modos de afectar y ser afectados que se deslizan sobre los cuerpos y el medio, haciendo patente los usos de cada uno, donde la vida, especialmente, en su creación y recreación se expresa como resistencia.

\section{Un cierre (si es) posible}

Intentamos cerrar, si es posible, pensando con la pregunta que establecen Delezue y Guattari (2002): "¿Qué relación hay entre lo imperceptible (anorgánico), lo indiscernible (asignificante) y lo impersonal (asubjetivo)?” (p. 281). Y frente a lo que se pregunta Deleuze podríamos preguntarnos nosotros: ¿qué es lo que lo hace esos conceptos inmediatamente políticos? Parte de la respuesta a estas preguntas se encontraría en su capacidad de transformación, metamorfosis, variación, deformación y desorganización que el arte provoca. Las zonas de indiscernibilidad que avivan devenires bajo la experimentación de variables de multiplicidad, sería una cuestión central en este devenir que se manifiesta como minoritario, como proceso de variación intensivo y eminentemente político el cual al escapar al control crea mundos posibles haciendo usos impensados de los elementos que los constituyen. El devenir es siempre un proceso minoritario; es cuestión de todo el mundo: "devenir todo el mundo es hacer del mundo un devenir, es crear una multitud, es crear un mundo, mundos, es decir, encontrar sus entornos y sus zonas de indiscernibilidad" (Deleuze \& Guattari, 2002, p. 281).

Basándonos en el recorrido presentado aquí, sí creemos que el devenir como potencia del arte y en su encuentro con la política siempre es minoritario en cuanto se enlaza inmediatamente con la resistencia y la creación. Son modos irreductibles que en su carácter difuso precipitan nuevos modos de pensamiento, nuevos modos de sentir, nuevos modos de vivir, los cuales batallan permanentemente contra la rostrificación; es decir, lo intolerable y la servidumbre. Los movimientos moleculares propios de este devenir minoritario son pensados, por Deleuze y Guattari, como "minorías", como formas colectivas de expresión, que permanentemente han de "combatir y socavar la gran organización mundial" (Deleuze \& Guattari, 2002, p. 220). ${ }^{17}$

De esta manera, las "minorías" han de continuar la lucha contra su completa adaptación a tales modos de subjetivación y rostrificación. Se afirman positivamente sin dejar de lado las intensidades y potencias propias que la constituyen: su devenir. Las minorías se escabullen dentro de tales estructuras de dominación y poder para llevar a cabo una socialización más profunda que nos permite pensar imbricados efectos políticos heterogéneos: y deshacer el rostro sería parte de esta nueva dimensión y proceso de las singularidades, las cuales introducen en el conjunto social una verdadera transformación e inagotabilidad de las instancias de resistencia y lucha.

16. Con base en esta cita de Sauvagnargues, es interesante mostrar en este punto central de la investigación, dos ejemplos artísticos que pueden "reflejar" (si eso es posible), la política del rostro deshecho que acá proponemos. Intentando concretar esta idea de los devenires minoritarios presentes en la resistencia artístico-política, es interesante confrontar la obra general de la artista visual Judith Scott (cuestión que también se hace interesante por su propia biografía), y la obra "The artist is present" de Marina Abromovic.

17. La noción de minoría debe entenderse como substrato inestable de carácter muchas veces inasignable. Razón que nos hace pensar en la desfiguración intrínseca que sufre cualquier forma unitaria y que expresa una proliferación de diversas prácticas irreductibles a tal lógica de gravedad unitaria y centrípeta como lo son los rasgos de rostridad. 


\section{Referencias}

Alliez, E. (2004). La condición CsO. O la política de la sensación. Revista Laguna, 15, 91-106.

Cuevas, L. H. (2016). Spinoza, Hegel, Deleuze y el problema de la inmanencia. Rev. Guillermo de Ockham, 14(2), 33-41.

Deleuze, G. (1994). Lógica del sentido. Barcelona: Paidós.

Deleuze, G. (1999). Conversaciones. Valencia: Pre-Textos.

Deleuze, G. (2002a). Diferencia y repetición. Buenos Aires: Amorrortu.

Deleuze, G. (2002b). Francis Bacon. Lógica de la sensación. Madrid: Arena Libros.

Deleuze, G. (2005). La isla desierta y otros textos, textos y entrevistas (1953-1974). Valencia: Pre-Textos.

Deleuze, G. (2007). Dos regimenes de locos, textos y entrevistas (1975-1995). Valencia: Pre-Textos.

Deleuze, G. (2008). La filosofia critica de Kant, Madrid: Ed. Cátedra.

Deleuze, G., \& Guattari, F. (2002). Mil mesetas. Valencia: Pre-Textos.
Deleuze, G. \& Guattari, F. (1983). Kafka. Por una literatura menor. México D.F. Ediciones Era.

Deleuze, G. \& Guattari, F. (1999). ¿Qué es la filosofía? Barcelona: Anagrama.

Deleuze, G. \& Guattari, F. (1998). El Anti-Edipo. Barcelona: Paidós.

Deleuze, G. \& Parnet, C. (1980). Diálogos. Valencia: Pre-Textos.

Mengue, Ph. (2008). Deleuze o el sistema de lo múltiple. Buenos Aires: Las Cuarenta.

Ordónez, L. (2011). Arte y acontecimiento. Una aproximación a la estética deleuziana. Revista latinoamericana de filosofia, 37(1), 127-152.

Pardo, J.L. (2002). Deleuze: violentar el pensamiento. Madrid: Ediciones Pedagógicas.

Sauvagnargues, A. (2006). Deleuze. Del animal al arte. Buenos Aires: Amorrortu

Sibertin-Blanc, G. (2010). Deleuze y las minorías: ¿cuál política?. En Y. Ch. Zarka (Eds.), Deleuze político (pp. 45-65). Buenos Aires: Nueva Visión.

Zourabichvili, F. (2004). Deleuze, una filosofía del acontecimiento. Buenos Aires: Amorrortu. 